\title{
Results obtained with a low cost software-based audiometer for hearing screening
}

\author{
Deborah Viviane Ferrari', Esteban Alejandro Lopez ${ }^{2}$, Andrea Cintra Lopes ${ }^{3}$, Camila Piccini Aiello ${ }^{4}$, Pricila Reis Jokura5. \\ 1) PhD in Neuroscience and Behavior - Institute of Psychology, University of São Paulo. Professor, Department of Speech Language Pathology and Audiology. Dentistry \\ School of Bauru - University of São Paulo. \\ 2) Clinical Engineer. Master in Biomedical Engineering - Favaloro University, Buenos Aires, Argentina. Favaloro University, Buenos Aires, Argentina. \\ 3) $\mathrm{PhD}$ in Communication Disorders - University of São Paulo. Associate Professor, Department of Speech Language Pathology and Audiology. Dentistry School of Bauru \\ - University of São Paulo. \\ 4) Speech Language Pathologist and Audiologist. Graduate Student - Master in Speech Language Pathology and Audiology. Dentistry School of Bauru - University of \\ São Paulo. \\ 5) Speech Language Pathologist and Audiologist. Graduate Student - Master in Speech Language Pathology and Audiology. Dentistry School of Bauru - University of \\ SãoPaulo. \\ Institution: Departamento de Fonoaudiologia. Faculdade de Odontologia de Bauru - USP. \\ Bauru / SP - Brazil. \\ Mailing address: Faculdade de Odontologia de Bauru - USP. Deborah Viviane Ferrari Al. Octávio Pinheiro Brisola 9-75. Vila Universitária - Bauru / SP - Brazil - Zip code: \\ 17012-901. E-mail: deborahferrari@usp.br \\ Article received on December 10 $0^{\text {th }}, 2012$. Article accepted on April $7^{\text {th }}, 2013$.
}

\section{SUMMARY}

Introduction: The implementation of hearing screening programs can be facilitated by reducing operating costs, including the cost of equipment. The Telessaúde (TS) audiometer is a low-cost, software-based, and easy-to-use piece of equipment for conducting audiometric screening.

Aim: To evaluate the TS audiometer for conducting audiometric screening.

Methods: A prospective randomized study was performed. Sixty subjects, divided into those who did not have (group A, $\mathrm{n}$ $=30$ ) and those who had otologic complaints (group B, n =30), underwent audiometric screening with conventional and TS audiometers in a randomized order. Pure tones at $25 \mathrm{~dB}$ HL were presented at frequencies of 500, 1000, 2000 , and 4000 Hz. A "fail" result was considered when the individual failed to respond to at least one of the stimuli. Pure-tone audiometry was also performed on all participants. The concordance of the results of screening with both audiometers was evaluated. The sensitivity, specificity, and positive and negative predictive values of screening with the TS audiometer were calculated.

Results: For group A, 100\% of the ears tested passed the screening. For group B, "pass" results were obtained in 34.2\% (TS) and $38.3 \%$ (conventional) of the ears tested. The agreement between procedures (TS vs. conventional) ranged from $93 \%$ to $98 \%$. For group B, screening with the TS audiometer showed $95.5 \%$ sensitivity, $90.4 \%$ sensitivity, and positive and negative predictive values equal to $94.9 \%$ and $91.5 \%$, respectively.

Conclusions: The results of the TS audiometer were similar to those obtained with the conventional audiometer, indicating that the TS audiometer can be used for audiometric screening.

Keywords: Hearing; Hearing Loss; Hearing Tests.

\section{INTRODUCTION}

Hearing loss is among the three most prevalent conditions worldwide, with around 636.5 million people suffering from a certain degree of hearing loss (1). It is estimated that in Brazil, $6.8 \%$ of the population suffers from disabling hearing loss, i.e., a hearing threshold level for the better ear of $41 \mathrm{~dB}$ HL or greater, averaged at frequencies of $0.5,1,2$, and $4 \mathrm{kHz}$. Of these individuals, $5.3 \%$ are children between 4 and 9 years old, 36.2\% are elderly, and $19.5 \%$ are adults between 20 and 59 years old (2). In the state of São Paulo, a population-based study showed that the prevalence of hearing loss was $44 \%$, being higher for elderly male individuals (3). A population-based crosssectional study performed in Rio de Janeiro showed that, for the elderly, the prevalence of hearing loss in the better ear was $42.9 \%$ (4).

Hearing loss can hinder or even impede acquisition and development of oral language, as well as academic and social development in children. In addition, it can decrease the quality of life and work and educational opportunities of adult individuals. This condition also has an impact on society in terms of loss of productivity of affected individuals as well as costs of treatment, education, and rehabilitation of people with special needs. Thus, healthcare actions focused on prevention, early identification, and treatment of hearing problems also have social and economic implications.

The Brazilian National Health System (Sistema Único de Saúde, SUS) has incorporated the treatment of the 
hearing impaired in previous decades. Such action was supplemented by the establishment of the National Hearing Healthcare Policy in 2004 (5) and, more recently, by the Care Network for People with Disabilities within the SUS (6). This network is organized into the components of primary care, specialized rehabilitation care, and emergency hospital care. Primary care services are provided through Healthcare Basic Units (UBS), which prioritize certain strategic actions intended to enhance access for and attention to people with disabilities, including the promotion of early identification services.

In Brazil, newborn universal hearing screening has been enforced by law since 2010 (7). However, progressive or late onset hearing losses are not detected at birth. It is estimated that 9-10 out of 1000 school aged children have permanent hearing loss in at least one ear (8). The Health in School Program (PSE), initiated in 2007 as a joint action between the Ministries of Health and Education, aims to incorporate the school community into projects and programs that make use of healthcare and education in order to comprehensively deal with the issues that compromise the development of Brazilian children and teenagers. The primary task of the PSE is the assessment of the health condition of students, including hearing status. In order to do so, audiometric procedures, among others, are recommended (9).

For adults and the elderly, hearing loss onset is often insidious, complicating self-perception of the problem and, consequently, the request for treatment. Performing hearing screening in this population would enable timely identification and corresponding referral to rehabilitation services, in order to minimize secondary consequences such as functional decline, depression, and social isolation.

In Brazil, there are still no large scale hearing screening programs targeting school aged children, adults, and the elderly. When screenings are conducted in this population, they are isolated events. The reasons for this scenario are multifactorial and include the costs of the procedure. The related costs can be attributed to the cost of the professional performing the procedure, the necessary time to perform it, and the cost of the necessary equipment. In order to decrease screening costs, a simple, fast, and effective method using low cost equipment that can be easily operated by a primary care professional must be utilized (10).

It is also necessary to emphasize the difficulty of access to hearing health for populations living far from urban centers. Thus, a relevant aspect of this scenario is the development of computer-based systems that can be used in telehealth models. Different low cost systems for conducting audiometric screening (11-13) or audiological assessment at distance (14-15) have been published in the literature. Such systems use TDH-39 supra-aural headphones or ER3A insert phones, which can increase device cost. One study was found on the use of a software-based screening audiometer that utilized a conventional circumaural phone with a $3.5 \mathrm{~mm}$ plug. However, this system was automatic and hearing responses were queried with $3 \mathrm{~dB}$ increments, making the test relatively lengthy with a duration of about 15 minutes (10).

The Telessaúde (TS) audiometer was developed to perform audiometric screening using off-the-shelf USB interface headphones. This characteristic has a relevant impact on acquisition and replacement costs (the prototype costs less than 50 USD) and also facilitates access of the user to the TS audiometer. A wide variety of USB headphones are available and the user can chose a model that is considered more convenient, once that set of headphones has been calibrated for use with the TS audiometer. The fact that only off-the-shelf electronic devices are used also facilitates the availability of the TS audiometer, as the eventual manufacturer will not require a specific infrastructure for manufacturing and distribution. The aim of this study was to evaluate the TS audiometer for use during audiometric screening.

\section{METHOD}

This randomized prospective study was conducted in the Speech Language Pathology and Audiology Clinic of the $\mathrm{X}$ School, University $\mathrm{X}$, and was approved by the relevant research ethics committee (process number 021/ 2010). This clinic is currently accredited by the SUS as a tertiary hearing healthcare service.

Once an informed consent form was signed by 60 individuals, aged 18 years or older, they were voluntarily enrolled in the study and segregated into 2 groups (Table 1):

- Group A: for this group, employees and graduate students of the Bauru School of Dentistry were invited to participate in the study. This group was composed of 30 adults with age varying from 18 to 41 years old. None of these individuals presented a hearing complaint.

- Group B: for this group, individuals who had ENT or audiological complaints and were referred to the clinic were invited to participate in the study. This group was comprised of 30 individuals with age ranging from 23 to 85 years old. There were 12 adults and 18 elderly subjects (aged 60 years or older). None of these individual had had their hearing assessed previously.

The TS audiometer is integrated by software developed in Visual Basic.NET 2005 (Net Framework 2.0) 
Table I. Demographic data of the participants.

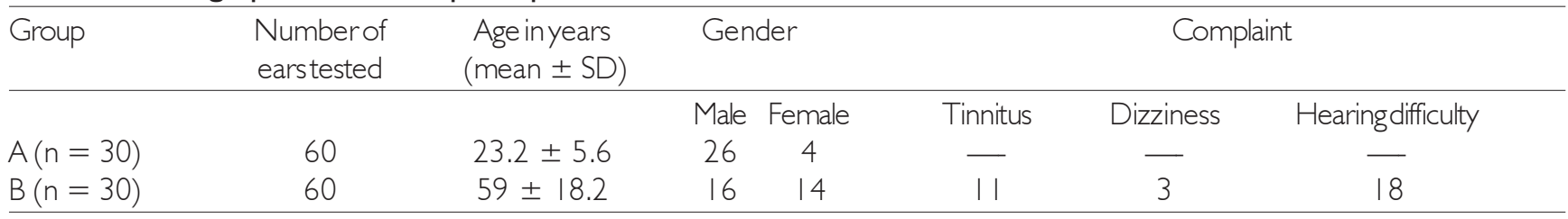

for Windows XP and a set of USB headphones. It is supported by a multiuser database system managed by an administrator. The system can store the registration information of the location where screening is performed, the information of the healthcare professionals (users) and screened populations, as well as the corresponding evaluation results. Figure 1 shows an example of a TS audiometer user interface.

With regards to hardware, the audiometer uses a Microsoft LifeChat LX-3000 headset with the following specifications: (a) bilateral earphones $(20 \mathrm{~Hz}-20 \mathrm{kHz})$; (b) embedded microphone (100 Hz-10 kHz); (c) embedded USB sound board with 16 bit precision; (d) plugandplay, i.e., no other software installation is needed for normal use; and (e) incorporated volume control. As for every USB device, the headset is identified by the host computer by its Vendor ID and Product ID, therefore allowing the software to apply the corresponding calibration parameter or impede the performance of the audiometric procedure if the corresponding parameters are not available.

Following FDA recommendations for signature of electronic records (16), the identity and electronic signature of the healthcare professional are protected by a password only known and modifiable by the healthcare professional. Additionally, a change control, or audit trail, is not deemed necessary, as once they are electronically signed, the assessment results can no longer be modified.

In this study, the TS audiometer was installed and tested in an ASUS EeePc900 laptop, given its relatively low cost and portability. This laptop has a 8.9" screen, a Celeron M353 processor, a 4 GB hard drive, 1 GB of DDR II RAM, an Intel UMA video board, a 1.3 megapixel webcam, a Windows ${ }^{\circledast}$ XP operating system, $802.11 \mathrm{~b} / \mathrm{g}$ WLAN, USB/VGA/Earphone/Mic/Network inputs/outputs, embedded loudspeakers, a battery autonomy of approximately 2.5 hours, dimensions of $22.5 \times 17 \times 2 \mathrm{~cm}$, and a weight of $0.99 \mathrm{~kg}$.

The TS audiometer includes a calibration user interface. This interface is only accessible for the testing prototype. Through this interface, the calibration parameters of a certain headset model can be determined and stored. These values are stored in the system parameters database

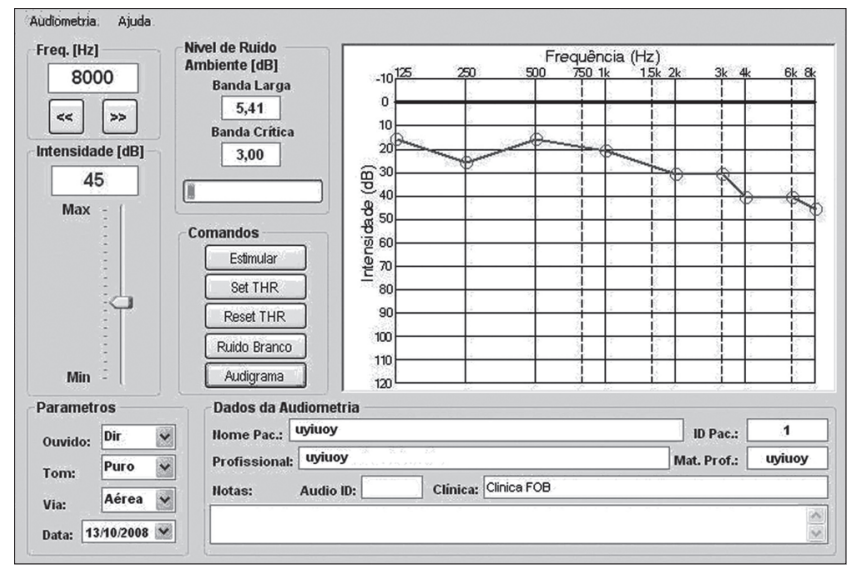

Figure 1. TS audiometer user interface.

and they are used every time an audiometric screening is performed. The device (computer and headphones) was calibrated by an engineer with experience in conventional audiometer calibration according to the applicable requirements of the standard project $\mathrm{ABNT} / \mathrm{CB}$ 03/CE03:029.01-022/1. The frequencies $250-8000 \mathrm{~Hz}$ were used to calibrate the left and right earphones of the Microsoft LifeChat LX-3000 headset. During calibration, the TS audiometer software was used to provide acoustic stimulation. With regard to the calibration, it must be noted that the USB headset included its own sound board, i.e., its own analog and digital input/output stages. Therefore, the calibration parameters were characteristic of the headset model and independent of the host computer model or type. The frequencies 250, 500, 1000, 2000, 3000, 4000, 6000 , and $8000 \mathrm{~Hz}$ were calibrated ranging from $10 \mathrm{~dB} \mathrm{HL}$ (minimum stimulation level) to $70 \mathrm{~dB}$ HL (maximum stimulation level) in $5 \mathrm{~dB}$ steps for both the right and left channels.

Another feature contemplated during development of the TS audiometer was the real-time estimation of ambient noise levels during performance of the screening procedure. As audiometric screening is not necessarily conducted in an audiometric booth or an acoustically prepared room, the TS audiometer uses the microphone embedded in the headset, placed in the upright position, to determine the ambient noise level. The software application converts the sampled noise level into a dB scale in order to assess if 
the real-time ambient noise level allows screening to be performed. The system will automatically display a message to the evaluator when the ambient noise level is greater than $60 \mathrm{~dB}$ SPL to make him/her aware that minimization of noise level is desirable. The system user interface will flag the responses obtained under an ambient noise level greater than $60 \mathrm{~dB}$ SPL and also stores the average ambient noise level measured during an evaluation on its database. This is intended to minimize the occurrence of false positives induced by the lack of an appropriate acoustic environment. As the screenings were conducted in a sound booth, this feature of the TS audiometer was not evaluated in the present study.

Audiometric screening was conducted in groups A and B with 2 different pieces of equipment: the SD 50 audiometer (Siemens) coupled with supra-aural THD-39 headphones and the TS audiometer. The screenings were conducted on the same day by 2 different audiologists, each one operating one audiometer. The audiologists did not share the results obtained with each other and they were not aware of the patients' hearing complaints. The procedures were conducted in a randomized order.

Audiometric screening was based on the ASHA protocol $^{17}$. Pure tones at frequencies of 500, 1000, 2000, and $4000 \mathrm{~Hz}$ were presented at a $25 \mathrm{~dB}$ HL level. The participant was instructed to raise his/her hand each time the acoustic stimuli were heard. In the audiometric screening, a "pass" result was considered when the subject responded to the stimuli presented. The result was considered "fail" when the subject did not respond to one or more stimuli presented in one or both ears.

Following audiometric screening, and regardless of the result (pass or fail), all participants underwent otologic inspection, pure-tone threshold audiometry, and speech audiometry procedures. For such purposes, SD 50 (Siemens) or Midimate 622 (Madsen) audiometers were used. Air conduction hearing thresholds were obtained with TDH-39 earphones for the inter-octaves of the frequencies between 250 and $8000 \mathrm{~Hz}$, for both ears. When the air conduction hearing thresholds were greater than $20 \mathrm{~dB} \mathrm{HL}$, bone conduction audiometry was also performed for the frequencies 500, 1000, 2000, 3000, and $4000 \mathrm{~Hz}$.

Hearing thresholds were determined by applying the ascendant-descendant strategy. At each pure-tone detection response, the presentation level was reduced by $10 \mathrm{~dB}$ until the individual no longer responded to the stimuli. Then, the presentation level was increased in $5 \mathrm{~dB}$ steps until a response was detected. The hearing threshold, at each frequency, was the lowest level at which the individual could detect $50 \%$ of the stimuli presented.
All procedures were performed in a sound booth, where the noise levels were within the specified ranges of the ANSI 1999 standard (18).

Concordance analysis and Cohen's kappa coefficient were used to analyze the screening results between the conventional and TS audiometers for groups A and B.

The precision of the TS audiometer screening instrument was evaluated through specificity, sensitivity, positive predictive value, and negative predictive value analysis. The sensitivity was defined as the percentage of ears that failed screening with the TS audiometer among those in which hearing loss was observed with pure-tone threshold audiometry. The specificity was defined as the percentage of ears that passed screening among those with normal hearing results. In this study, air conduction audiometric thresholds less than or equal to $20 \mathrm{~dB}$ HL were considered as normal hearing. The positive and negative predictive values were defined as the probability of a patient having hearing loss if they failed screening and the probability of a patient having normal hearing if they passing screening, respectively.

\section{RESULTS}

With regard to group $B$, the number of individuals that failed the screening was 27 with the TS audiometer and 26 with the conventional audiometer.

Within group B, 4 participants presented normal hearing at all frequencies. The other 26 participants presented different degrees of sensorineural hearing loss (Figure 2), as per the pure-tone and speech audiometry results.

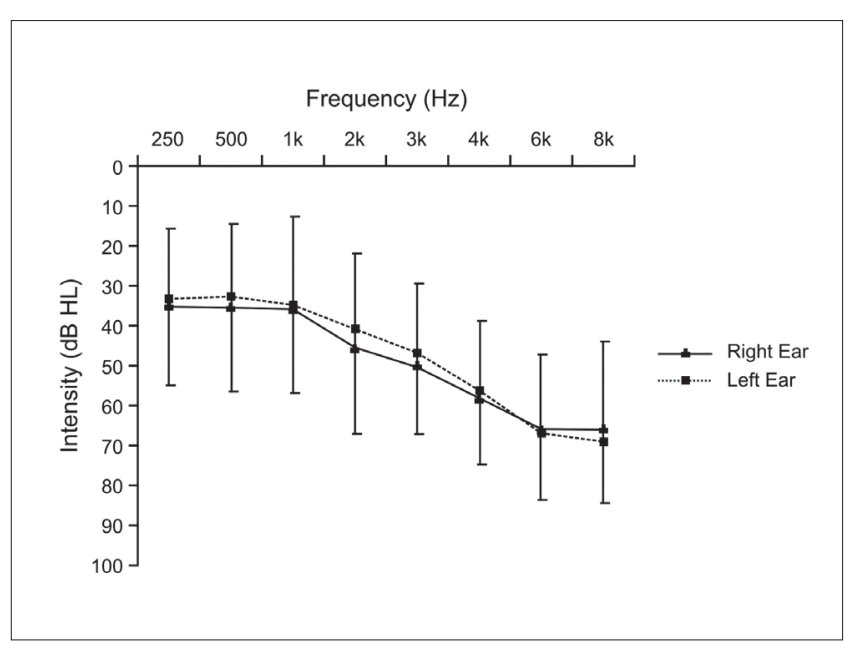

Figure 2. Mean and standard deviation of audiometric thresholds for participants who presented hearing loss $(n=26)$. 
Table 2. Audiometric screening and concordance results for group $A(n=60$ ears).

\begin{tabular}{|c|c|c|c|c|c|}
\hline \multirow{2}{*}{ Frequency $(\mathrm{Hz})$} & \multicolumn{2}{|c|}{ TSaudiometer } & \multicolumn{2}{|c|}{ Conventional audiometer } & \multirow[t]{2}{*}{ Concordance(\%) } \\
\hline & Pass & Fail & Pass & Fail & \\
\hline 500 & 60 & 0 & 60 & 0 & 100 \\
\hline 1000 & 60 & 0 & 60 & 0 & 100 \\
\hline 2000 & 60 & 0 & 60 & 0 & 100 \\
\hline 4000 & 60 & 0 & 60 & 0 & 100 \\
\hline Total (\%) & $240(100)$ & $0(100)$ & $240(100)$ & $0(100)$ & 100 \\
\hline
\end{tabular}

Table 3. Audiometric screening and concordance results for group $B(n=60$ ears).

\begin{tabular}{lcccccc}
\hline Frequency $(\mathrm{Hz})$ & \multicolumn{2}{c}{ TSaudiometer } & \multicolumn{2}{c}{ Conventional audiometer } & Concordance(\%) & Kappacoefficient \\
& Pass & Fail & Pass & Fail & & \\
\hline 500 & 32 & 28 & 32 & 28 & 98.31 & 0.97 \\
1000 & 24 & 36 & 28 & 32 & 93.33 & 0.86 \\
2000 & 20 & 40 & 22 & 38 & 96.67 & 0.93 \\
4000 & 06 & 54 & 10 & 50 & 96.33 & $0.7 \mid$ \\
\hline Total (\%) & $82(34.2)$ & $158(65.8)$ & $92(38.3) \mid 48(61.4)$ & 96.67 & 0.84 \\
\hline
\end{tabular}

\section{DISCUSION}

In group A (Table 2), all tested ears passed the screening. Although the sample size was limited, this observation is supported by the fact that the participants were predominantly young females, a population for which the prevalence of hearing loss is smaller (2-3). The concordance between the screening results obtained with the conventional and TS audiometers was excellent.

In group $B$ (Table 3), most ears failed the screening with both audiometers. It is worth noting that this group of participants had some kind of otologic complaint, with 18 of them reporting hearing difficulties. This group was also mostly composed of elderly subjects, for whom a greater prevalence of hearing loss is observed (2-4). Thus, a considerable number of failures were expected.

The number of failures at the frequency of $500 \mathrm{~Hz}$ was less than that for the other frequencies, which contradicts results reported in the literature (10). This can be explained by the fact that the screening was conducted in a sound booth, this being a limitation for the generalization of the data from the current study. In fact, hearing screening is generally conducted in a non-acoustically isolated room. Consequently, ambient noise can exert a masking effect over emitted signals, which is more significant at low frequencies, thus affecting screening results at these frequencies. For this reason, several screening protocols exclude the $500 \mathrm{~Hz}$ test, although this frequency is relevant for the assessment of the impact of middle ear condition on hearing sensitivity.
In Table 3, the kappa coefficients show an excellent concordance between the evaluators for the screening results obtained with the conventional and TS audiometers at the frequencies of $500 \mathrm{~Hz}$ to $3000 \mathrm{~Hz}$, and substantial concordance for the frequency of $4000 \mathrm{~Hz}$ (19). The interevaluator reliability allows verification of the degree of correspondence between the independent evaluations of 2 or more evaluators classifying the same phenomena. Therefore, it is a relevant indicator of the quality of the screening procedure with the TS audiometer. Previously, kappa coefficients of 0.79-0.93 were observed when evaluating the concordance between audiometric screenings conducted with a portable audiometer and a conventional audiometer ${ }^{20}$. Another study ${ }^{10}$ indicated a kappa coefficient of 0.20 between screening performed with a software-based audiometer and a conventional one. The fact that this result is lower than the one obtained in the current study could be related to the population characteristics (school aged children) and the impact of ambient noise at the frequency of $500 \mathrm{~Hz}$, since when this was excluded from the analysis, a kappa value of 0.62 was obtained. Another important difference is that an automatic screening procedure was employed in the previous study, in contrast with the conventional procedure utilized in the current study.

In Table 4, it can be observed that audiometric thresholds for group A were within normal values. Audiometric thresholds greater than $25 \mathrm{~dB}$ HL were found for at least one frequency in $65.4 \%$ of the ears tested in group B. For this group, 26 participants (86.6\%) presented sensorineural hearing loss, with a greater involvement of the high frequencies (Figure 2). This high incidence of 
Table 4. Distribution of the number of ears with normal thresholds and hearing loss in both groups.

\begin{tabular}{lcccc}
\hline Frequency $(\mathrm{Hz})$ & \multicolumn{2}{c}{ Group $\mathrm{A}(\mathrm{n}=60$ ears $)$} & \multicolumn{2}{c}{ Group $B(\mathrm{n}=60$ ears $)$} \\
& Normal & Hearing loss & \multicolumn{2}{c}{ Normal Hearing loss } \\
\hline 500 & 60 & 0 & 29 & 31 \\
1000 & 60 & 0 & 29 & 31 \\
2000 & 60 & 0 & 19 & 41 \\
4000 & 60 & 0 & 6 & 54 \\
\hline Total $(\%)$ & $240(100)$ & $0(0)$ & $83(34.6)$ & $157(65.4)$ \\
\hline
\end{tabular}

Table 5. Specificity, sensitivity, positive predictive value, and negative predictive value for TS and conventional audiometers.

\begin{tabular}{|c|c|c|c|c|c|}
\hline \multirow[t]{2}{*}{ Audiometer } & \multirow[t]{2}{*}{ Group } & \multirow[b]{2}{*}{ Sensitivity } & \multirow[b]{2}{*}{ Specificity } & \multicolumn{2}{|c|}{ Predictive value } \\
\hline & & & & Positive & Negative \\
\hline \multirow[t]{2}{*}{ TS } & $A$ & - & $100 \%$ & - & $100 \%$ \\
\hline & B & $95.5 \%$ & $90.4 \%$ & $94.9 \%$ & $91.5 \%$ \\
\hline \multirow[t]{2}{*}{ Conventional } & A & - & $100 \%$ & - & $100 \%$ \\
\hline & B & $91.1 \%$ & $94 \%$ & $96.6 \%$ & $84.8 \%$ \\
\hline
\end{tabular}

hearing loss is due to the fact that the participants of this group were recruited from a specialized hearing healthcare clinic. It is relevant to note that all of the subjects who presented hearing loss underwent a complete audiological assessment and received corresponding treatment, including fitting of hearing aids.

Pure-tone audiometry is currently the gold standard for assessment of hearing sensitivity. Therefore, the sensitivity and specificity of the screening procedures with the conventional and TS audiometers (Table 5) were calculated using the results obtained with pure-tone threshold audiometry as a reference. It was not possible to calculate the sensitivity of the procedures for group A due to the fact that none of the participants failed the screening or presented hearing loss with pure-tone audiometry. The specificity of this group equaled 100\% for both procedures. For group B, the sensitivity and specificity values of the TS audiometer were similar to those of the conventional audiometer (Table 5). Elevated sensitivity and specificity values avoid the occurrence of false negatives and false positives, respectively. However, it must be remembered that no procedure is entirely accurate, i.e., no procedure has a sensitivity and specificity equal to $100 \%$.

The sensitivity and specificity values of the TS audiometer were similar to those found in the literature. The sensitivity and specificity of a portable screening audiometer were reported to be 91.8-98.5\% and 88.0$96.3 \%$, respectively (20). Studies involving the Audioscope device with pure-tone sweep (500 to $4000 \mathrm{~Hz}$ ) for hearing screening demonstrated a sensitivity of $94-97 \%$ and a specificity of 69-80\% (11). With regards to affordable audiometers, the TS audiometer presented higher sensitivity and specificity values than those found in the literature. Sensitivity and specificity values of $86.7 \%$ and $75.9 \%$ were verified with a remote automatic audiometric screening method (20 dB HL pure-tone sweep), based on the use of a computer and TDH-39 earphones (13). Automatic hearing screening conducted with a low cost audiometer and a circumaural phone showed a sensitivity of 100\% and a specificity of $49 \%$ (10). The differences observed between the literature and the present study can be related to the stimuli loudness level applied in the current study ( $25 \mathrm{~dB}$ $\mathrm{HL}$ ), attenuation differences in the earphones utilized, and, mainly, the screening method (automatic vs. manual) and screening room acoustics (non-acoustically isolated room vs. audiometric booth) used.

Under operational conditions (field application), the performance indicators of a test procedure are modified by the frequency of occurrence of a medical condition within the population (prevalence). Therefore, the predictive value of the procedure has a significant relevance, i.e., the probability of occurrence of a medical condition given a positive or negative result. In the current study, the positive and negative predictive values of the TS audiometer were equal to $94.9 \%$ and $91.5 \%$, respectively, being similar to those obtained with a conventional audiometer (Table 5). This means that if a subject fails screening with the TS audiometer, there is a $94.9 \%$ chance of them actually suffering from hearing loss and a 5.1\% (100-94.9) chance of them having normal hearing. If the subject passes 
screening, there is $91.5 \%$ chance of them having normal hearing and an 8.5\% (100 - 91.5) chance of them having hearing loss.

For group B, the observed predictive values of the TS audiometer were greater than those found in the literature for other affordable audiometers, which presented positive and negative predictive values of $48.1 \%$ and $95.7 \%{ }^{13}$ and $56 \%$ and $43 \%{ }^{10}$, respectively. These findings are justified by the differences observed in the sensitivity and specificity of the TS audiometer when compared to other audiometers, and the fact that the screened population was from a specialized hearing healthcare clinic, where a higher number of subjects with hearing loss were registered.

Screening programs are justified if there is evidence that sustains 3 standard criteria: (a) negative consequences of the medical condition must be sufficiently significant in order to justify the screening effort; (b) an effective treatment for the detected medical condition is available; and (c) an accurate, practical, and convenient screening test is available ${ }^{11}$. Although this study is limited by the number of participants, the results obtained suggest that the TS audiometer meets the necessary criteria for a screening procedure.

\section{CONCLUSION}

The specificity, sensitivity, and positive and negative predictive values of audiometric screening conducted with the TS audiometer were high and similar to those obtained with a conventional audiometer.

\section{ACKNOWLEDGEMENTS}

The authors would like to thank Audiologist X for her support during data collection and Engineer Xfor performing the calibration of the TS audiometer.

\section{REFERENCES}

1. World Health Organization (WHO). The Global Burden of Disease [Internet]. 2004 [cited 2010 Jul 03]. Available from: http://www.who.int/healthinfo/global_burden_ disease/GBD_report_2004update_part3.pdf

2. Béria JU, Raymann BCW, Gigante LP, Figueiredo AL, Jotz GP, Roithmann R, et al. Hearing impairment and socioeconomic factors: a population-based survey of an urban locality in southern Brazil. Pan American Journal of Public Health. 2007;21:381-7.
3. Castro SS, César CLG, Carandina L, Barros MBA, Alves MCGP, Goldbaum M. Deficiência visual, auditiva e física: prevalência e fatores associados em estudo de base populacional. Cad. Saúde Pública. 2008;24(8):1773-82.

4. Mattos LC, Veras RP. Prevalência da perda auditiva em uma população de idosos da cidade do Rio de Janeiro: um estudo seccional. Rev. Bras. Otorrinolaringol. 2007;73(5):654-9 .

5. BRASIL, Ministério da Saúde. Portaria n $\square 2.073$ de 28 de setembro de 2004. Institui a política nacional de saúde auditiva [Internet]. [cited 2012 Oct 12]. Available from: http:/ /dtr2001.saude.gov.br/sas/PORTARIAS/Port2004/GM/GM2073.htm

6. BRASIL, Ministério da Saúde. Portaria n $\square 793$ de 24 de abril de 2012. Institui a Rede de Cuidados à Pessoa com Deficiência no âmbito do Sistema Único de Saúde [Internet]. [cited 2012 Oct 12]. Available from http:// bvsms.saude.gov.br/bvs/saudelegis/gm/2012/ prt0793_24_04_2012.html

7. BRASIL, Presidência da República. Lei n $\square 12.303$ de 02 de agosto de 2010. Dispõe sobre a obrigatoriedade de realização do exame denominado Emissões Otoacústicas Evocadas [Internet]. [cited 2012 Oct 12]. Available from http:/ /www.planalto.gov.br/ccivil_03/_Ato2007-2010/2010/Lei/ L12303.htm

8. Shargorodsky J, Curhan SG, Curhan GC, Eavey R. Change in prevalence of hearing loss in US adolescents. J. Am. Med. Assoc. 2010;304(7):772-8.

9. BRASIL, Ministério da Saúde. 2009. Saúde na Escola - Série B. Textos Básicos de Saúde-Cadernos de Atenção Básica, n. 24 [Internet]. [cited 2012 Oct 12]. Available from: http:/ /bvsms.saude.gov.br/bvs/publicacoes/cadernos_atencao_ basica_24.pdf

10. McPherson B, Law MMS, Wong MSM. Hearing screening for school children: comparison of low-cost, computer-based and conventional audiometry. Child: care, health and development. 2010;36(3):323-31.

11. Yueh B, Shapiro N, MacLean CH, Shekelle PG. Screening and management of adult hearing loss in primary care: scientific review. JAMA. 2003;289(15):1976-85.

12. Choi JM, Lee HB, Park CS, Oh SH, Park KS. PC-based tele-audiometry. Telemed J E Health. 2007;13(5):501-8.

13. Campelo VES, Bento RF. Teleaudiometria Automática: Um Método de Baixo Custo para Triagem Auditiva. Arq. Int. Otorrinolaringol. 2010;14(1):82-9. 
14. Givens DG, Blanarovich A, Murphy T, Simmons S, Blach D, Elangovan S. Internet-based tele-audiometry system for the assessment of hearing: a pilot study. Telemed J E Health. 2003;9(4):375-8.

15. Swanepoel DW, Koekemoer D, ClarkJ. Intercontinental hearing assessment - a study in tele-audiology. J. Telemed. Telecare. 2010;16(5):248-52.

16. Food and Drug Administration (FDA). 1997. Code of Federal Regulations Title 21: Food and drugs chapter I Food and drug administration department of health and human services subchapter a - general - Part 11: Electronic records; electronic signatures [Internet]. [cited 2012 Oct 12]. Available from: http://www.accessdata.fda.gov/scripts/ cdrh/cfdocs/cfcfr/cfrsearch.cfm?cfrpart $=11$
17. American Speech-Language-Hearing Association (ASHA). 1997. Guidelines for Audiologic Screening [Guidelines - Internet]. [cited 2012 Oct 12]. Available from. Available from: www.asha.org/policy.

18. ANSI. Maximum Permissible Ambient Noise Levels for Audiometric Test Rooms. American National Standards Institute, S3.1-1999, 1999, New York.

19. Landis, JR.; Koch, GG. The measurement of observer agreement for categorical data. Biometrics. 1977;33:159-74.

20. Wang YF, Wang SS, Tai CC, Lin LC, Shiao AS. Hearing screening with portable screening pure-tone audiometer and distortion-product otoacoustic emissions. Chinese Medical Journal. 2002;65(6):285-92 